\title{
Involving Consultants in Library Change
}

\begin{abstract}
Most of the literature about consultants in the field of academic librarianship relates to the construction of library facilities. By combining pointers from the business field, where application of the consulting engagement has touched upon a broader range of activities, a more general discussion is presented regarding the need and preparation for and the selection of library consultants. These activities are presented as steps in the organizational change process. First, a decision model is presented for determining the need for a library consultant. Second, preparation for the consulting engagement is discussed. Finally, recommendations are set forth for the selection of an appropriate consulting firm or individual.
\end{abstract}

I F WE WERE TO PARAPHRASE the Association of Consulting Management Engineers' definition of a management consultant, we might arrive at the following definition for a library consultant:

A library consultant may be defined as an individual qualified by education, experience, technical ability, and temperament to advise or assist on a professional basis in identifying, defining, and solving specific library problems involving the organization, planning, direction, control, and operation of a library. The consultant serves the library as an impartial, objective advisor and is not an employee of its organization. ${ }^{1}$

Robert Rohlf, director of Minnesota's Hennepin County Library, and a noted library consultant, distinguishes the role of the consultant by drawing a line between those who work on a project from its inception to the final

James $D$. Lockwood is reference librarian, Law Library, Indiana University, Bloomington. assessment and those who simply provide advice or assistance at a particular point in the process. ${ }^{2}$ The latter is termed a "critic" by Rohlf.

If we accept this basic definition, along with the distinction between "critic" and consultant, we then might ask what roles consultants have played in library change.

The role of the consultant, as opposed to the critic, has evolved largely since the mid-1950s and the passage of the Library Services and Construction Act. Thus, from the beginning, library consultants have been associated with the construction of library facilities. ${ }^{3}$

The increasing complexity of library services and operations has meant that the successful building project was the one whose every aspect was scrutinized, both in terms of the present and the future. Given such diverse concerns as audiovisual materials, microforms, computer processing, aesthetics, security, acoustics, lighting, ventilation and temperature control, legal requirements, differing managerial styles, and changes in nearly every facet of library opera- 
tions, it is understandable that outside experts were engaged to assist in the entire planning and construction process.

The construction boom no longer proceeds at the rate it did in the 1960s. Changes in services and operations, however, are continually being considered, planned, and put into action. Specialists still are being called upon, but the literature on the use of these specialists refers largely to construction projects. It is precisely for this reason that literature from business, where application of the consulting engagement has touched upon a broader range of activities, is drawn upon to round out our view of the use of outside assistance.

This paper is designed as a guide to librarians considering possibilities for undertaking some form of organizational or physical change. Be it a change in library facilities, services, or operations, it will do the planning body of the library well to consider systematically the need for a consultant. The first section of the paper presents a model designed to aid in that attempt. Once this has been done, if the decision has been made to seek the services of an outside consultant, it will be in the best interests of the library staff and users for that same planning body to prepare for the consulting engagement and to design a suitable selection process. The latter two sections of the paper deal with these two steps, respectively.

The basic change process for most libraries will begin with the awareness, on the part of the director or other person in a position of major responsibility, of a need for change. The director will, quite likely, rely on input and assistance from all individuals responsible for areas in which there appears to be a need for change. As formally constituted, this group will be called the planning committee for the sake of uniformity. For the most part, groups of this nature will proceed through a process such as that outlined below:

\section{Planning Committee}

A. Definition of the problem in terms of the objectives

B. Determination of the necessity for a consultant

C. Preparation for the consulting engagement

D. Selection of consultant(s)

II. Planning Committee and the Con$\operatorname{sultant}(s)$

A. Review and redefinition of the problems and objectives

B. Development of alternative solutions

C. Evaluation of alternatives and selection among them

D. Development of action plan, including feedback mechanisms

E. Implementation of project, with adjustments as necessary

F. Assessment of results obtained and procedure used

The three steps which this paper addresses are IB, C, and D. We will consider the determination of need for outside assistance and then proceed to the latter two phases of the process. It should be noted that in most instances where consultants are not engaged the process moves directly from IA to IIB.

\section{Determining the NeEd For Assistance From Outside the Library}

When considering prospects for change, regardless of its nature, there is usually some concern over how important decisions are made. Who should be involved, what data are necessary to support given alternative solutions, and similar concerns are commonly voiced.

The numerous benefits of the use of consultants have been spelled out clearly in the literature of both library science and business. ${ }^{4}$ Briefly, these include new ideas, fresh approaches, analytic ability, specialized skills and experiences, superior ability to introduce and implement change, ability to work on a specific problem with all resources at 
one time, objectivity (both for political reasons of corroborating a desired point of view and in the sense of "no conflict of interest"), more up-to-date knowledge, and the fact that consultants are not permanent burdens to the organization's payroll.

Each of these potential benefits falls under one of three broad categories: skills and abilities, time factors, and objectivity and influence. Each of these dimensions will have considerable bearing on decision-making. If the objective is a well-chosen change program, appropriately introduced, then the quality of decisions throughout the entire process is of utmost concern.

In terms of increasing the quality of decisions, three factors operate that already might exist to the fullest extent necessary for the particular undertaking. The quality of the decisions made throughout the process outlined above is a function of (1) the number of alternatives considered, (2) the accuracy of the predictions about the consequences resulting from selecting each alternative, and (3) the nature and efficiency of the feedback mechanisms provided (allowing adjustments resulting from corrections, changes, etc.).

That is, all of the potential advantages could be present in the library to begin with, or adding a position for an individual processing the desired qualities may be possible. Some organizations, for example, believe it possible to set up internal consulting groups within their company, thus allowing for internal objectivity. ${ }^{5}$ This is viewed as increasing the number of alternatives considered and the accuracy of the predictions about the consequences of each.

The four basic sources of assistance for increasing the quality of decisions made during the change process are:

Internal

I1: Utilize present staff

I2: Add a specialist to the staff

\section{External}

E1: Engage a critic to review and provide assistance for a particular part of the program

E2: Engage a consultant (firm or individual)

Figure 1 presents a decision model based upon these four sources. It is important to note that although no one model or set of considerations can apply for all types of libraries or programs, there are several important steps that take place in assessing any library's situation.

The model is essentially a contingency model. As was stated above, it is quite possible that a given library might have all of the qualities and resources allowing the planning committee to arrive at high quality decisions. The ability to take advantage of this, however, is contingent upon the time considerations present. If prompt action is critical or if the use of staff time will severely curtail services, then it still may be wise to obtain assistance from outside.

The considerations, expressed in question form, are arranged along the top of the figure. To use the model for assistance in arriving at a decision, one moves along the decision tree from left to right. Barring the presence of any overriding external factors, the symbol at the terminal node designates one of the prescribed alternatives noted above. A discussion of the rationale of each of the twelve outcomes follows the description of each consideration.

The first two considerations in Figure 1 ( $A$ and $B$ ) focus on the locus of the expertise, which is important in assuring the likelihood of high quality decisions. Does it reside within the organization, or must it be obtained from outside?6 Consideration B simply assures economy in cases where expertise in most aspects of the project is already present. Consideration $\mathrm{C}$ is a second factor, further clarifying the temporariness-permanence dimension of the needed skill.

Time (Consideration D) is, in effect, 

Is expertise lacking only in one part of entire
project?
Is time a crucial factor?
staff time limited or
prompt action necessary)

Library staff possess all expertise necessary to

make high quality

decisions?

D

Is objectivity in only one part of project

acceptable?
B

Is expertise needed fo specified period only?
Is objectivity a

crucial factor?

A

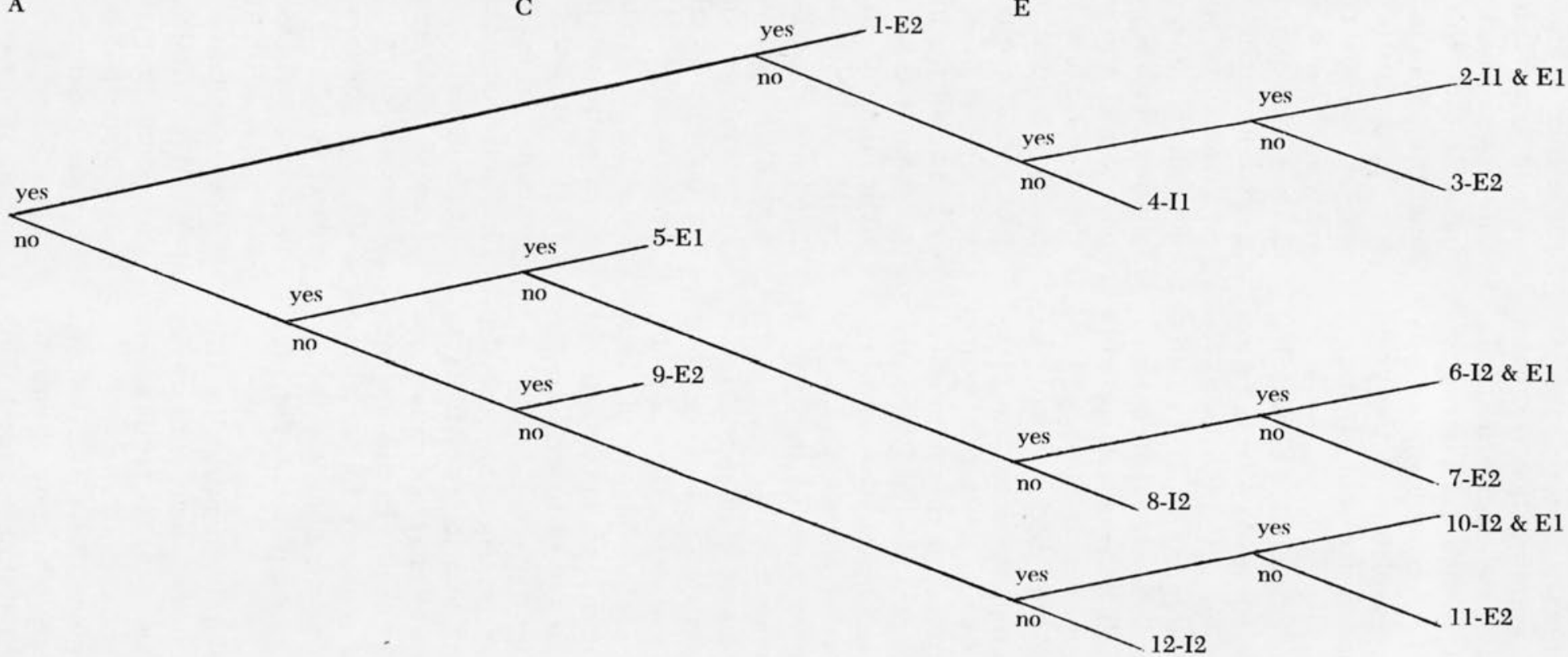

Fig. 1

Decision Model for Determining the Need for a Consultant 
a measure of urgency and priority. As stated above, if prompt action is crucial (that is, if delays are costly to the library or its users), then outside help is sought, or there is a restructuring of priorities, e.g., the completion of the project overrides concern for staff assistance to the user.

The final two questions ( $\mathrm{E}$ and $\mathrm{F}$ ) must be considered while keeping two outcomes in mind. If objectivity is preferable for the purpose of (1) obtaining responsible analysis of data or of a particular situation or (2) providing an outside opinion because powerful decision-making bodies may be skeptical of internal opinions (i.e., perceived lack of quality decisions), then $\mathrm{E}$ must be answered in the affirmative. Consideration $\mathrm{F}$ provides for economy, as in cases where objectivity only is required at a particular phase.

The rationale for each of the twelve outcomes is as follows:

1-E2 If the present staff possess the necessary expertise, a lack of time alone is sufficient cause for obtaining outside help. If the quality of decisions is to be maintained, then we need not go so far as to explore the question of objectivity.

2-I1 \& E1 The presence of expertise within the staff and its availability in terms of time still may not satisfy objectivity requirements. In this instance objectivity is required for only one part of the project, allowing the external critic to supplement the present staff.

3-E2 Outcome 3 is identical to Outcome 2, except that objectivity throughout the project requires the engagement of a consultant.

4-Il This solution allows full reliance on present staff, who possess both the expertise and the time required, while objectivity is not crucial.

5-E1 If expertise is lacking but for only one segment of the undertaking, the next question becomes, "Is exper- tise required on a temporary or permanent basis?" In this case a critic can provide short-term aid in one segment of the project. Since a critic is one from the outside, the provision for objectivity is met without pursuing the two final considerations.

6-I2 \& E1 This is identical to Outcome 5 , but the permanence of the required expertise calls for the hiring of a competent specialist. This can be done in this instance since objectivity, although crucial, is only necessary to one part of the project. The result is that a critic may be employed for segments requiring objectivity. This supplements the qualities of the specialist.

7-E2 The distinguishing factor in this outcome is the requirement for objectivity throughout the project, while at the same time the limits of the need for expertise cannot be specified. Such a situation has no inexpensive solution. To assure objectivity, an outsider usually is deemed desirable. Nonetheless, over a lengthy period, outsiders may lose a degree of objectivity as well. Such instances may require a series of competent consultants. An example is a case requiring a specialist in affirmative action implementation, who for political reasons must remain outside the library's employ.

8-I2 This solution is identical to Outcome 5 , but the need for expertise on a permanent basis calls for the hiring of a specialist even when objectivity is not essential.

9-E2 When desired expertise is lacking for significant portions of a project and when the period of required expertise is delineated, then we have the classic consulting situation. Time and objectivity need not enter into consideration, as sufficient cause for aid on a temporary basis from outside the organization already exists.

10-I2 \& E1 The three final outcomes 
all represent a condition wherein expertise is lacking in a significant portion of the project, and that expertise will be required for an indefinite period. In Outcome 10, a suitable solution can be achieved by hiring a specialist, supplementing this individual's expertise with the objectivity of a critic in the part of the project requiring that quality.

11-E2 The circumstances in Outcome 10 become considerably modified when objectivity is crucial throughout the project. This is a more extreme version of the circumstances presented in Outcome 7. As with Outcome 7, filling this need may prove to be expensive to the library.

12-I2 In the final outcome, seeking a permanent specialist represents the ideal solution. What is called for is relatively broad based expertise in a given area over an indefinite period. Since objectivity is not a requisite, employing the specialist will assure the continuity of skills desired.

Through use of the considerations noted in Figure 1, a decision to utilize any one of the four basic sources of assistance could be reached. The remaining sections of the paper, while relevant to I2 and E1, assume that E2 is the prescribed solution. If the consultant is truly necessary, for any of the reasons stated above, the planning committee would do well to prepare for the rigor of a well-designed selection process and for the peculiarities of a consultancy relationship. The nature of a consultancy relationship calls for careful consideration of factors not normally taken into account in the hiring of regular staff.

\section{Preparation for the Consulting ENGAGEMENT}

Preparation for a consulting engagement begins immediately upon the decision to seek the services of a consulting individual or firm. This section of the paper will present a series of steps through which the planning committee may increase the probability of a successful consulting engagement.

It is assumed by this point that all persons within or related to the library are aware of efforts being made to effect changes in the library. It also should be the case that these individuals are cognizant of the reasons for selecting someone from outside the library in order to achieve these changes more efficiently and effectively. This not only increases comprehension, thus allowing the library staff to be supportive, it also aids in the acceptance of the final recommendations.

This last statement may seem manipulative, but it is fair to say that this is the stage where the staff should be reminded to anticipate and facilitate change.

There are two major goals in the preparation for the consulting engagement. The first is to arrive at an agreement as to the planning committee's expectations of the consulting relationship. These might be called topics of mutual obligation and agreement. Once this has been done, a selection process should be designed to facilitate the identification and selection of a qualified consultant.

In terms of the first goal, it is important to be prepared to inform the consultant (in written form) of these expectations as well as to insure that the members of the committee come to an agreement among themselves.

Table 1 outlines the usual topics that the committee must take into account. As the nature of the change being undertaken may vary considerably, some of these might best be illustrated.

The first topic, the nature of the problem and the approach to the solution, while seemingly arrived at prior to the determination of the need for outside assistance, may need to be stated again. In most cases, and particularly 
TABLE 1

Topics of Mutual Obligation and Agreement to Be Considered

1. Nature of the problem and general approach to the solution

2. Particular constraints present

3. Library liaison assigned

4. Time schedule for project
A. Length
B. Phases
C. Portion of project consultant is involved with
D. Length of workday
E. Concurrent involvement in other activi- ties

5. Subcontracting of particular portions of project

6. Final report
A. Deadline
B. Nature (e.g., oral or written)
C. Confidentiality
D. Other factors

7. Fees
A. Type of fee arrangement
B. Fee estimate
C. Schedule of payments

8. Additional assistance to be provided by the library
A. Travel expenses
B. Materials and supplies
C. Office and secretarial needs
D. Special research needs

those requiring objectivity, this assures greater likelihood of a successful venture. When soliciting proposals, a brief statement of the problems will be necessary.

The particular constraints of the situation may not be obvious at this point. Many of them will, however, revolve around the elements of policy, philosophy of service, budgetary limitations, time, and space.

It is generally advantageous to select a library liaison, keeping a variety of factors in mind. First, it is important to specify simultaneously the roles of the liaison, the consultant, the committee, and the director. Where will the final authority lie? Will the consultant be responsible for the project with only specified exceptions, or will the consultant be performing an advisory function only? The Vroom article presents a model for rationally considering the important factors involved in decisions of this type. ${ }^{7}$

In any case, the liaison should be someone who is not only influential and knowledgeable but also accessible and personable. A second person should be designated in the event of the liaison's absence.

The fourth topic, that of time, has several important facets. Maximum and minimum estimates of length are a necessity, while particular phases or milestones must be preset to allow for the measurement of progress. Not all consultants begin at the start of a project nor carry through with follow-up studies after its completion. Any such expectations should be made clear as soon as possible.

Also under the time dimension come two concerns that typically arise after work has begun, thus causing hard feelings. The first is that of establishing an agreement on the length of a workday. Many employers of consultants focus most of their energies on the determination of the fee, only to learn that agreement on a per diem basis is of limited value without some agreement on the definition of a workday. The second sensitive area, like the first, is not a difficult problem as long as it is considered during the selection process and not after the project is half-completed, and that is the need to determine what other activities the consultant expects to be participating in at the time. If the individual is a library director or has other engagements, it is fair to ask how these will be handled concurrently and if they will cause any undue delay.

One last comment on time: The committee should privately agree as to the specific circumstances in which they would seek termination of the consulting engagement.

Subcontracting is a concern in two basic ways. It is important to know the weak points of a consultant prior to the 
final selection. If data are to be analyzed or air conditioning checked, it would be advantageous to know whom the consultant has in mind as a subcontractor for these specialized analyses.

Sixth, the nature of the final report should be spelled out clearly. It may be that none is necessary. If one is, then any deadline should be specified, along with a statement as to the number of copies, confidentiality, the nature and number of oral presentations accompanying it, and some discussion as to copy or distribution rights.

The topic of fees often receives more emphasis than it is due. Throughout the literature there are claims by former employers of consultants, as well as by consultants themselves, stating that (1) if the library needs a consultant in the first place and (2) if it is careful in its selection and in its subsequent relationship, it probably will find that the consultant services are worth much more to the library than the actual fee paid. There are numerous discussions in the literature of types of fees and some of the related ethical concerns. ${ }^{8}$ Whatever the fee arrangement, it is best to establish, in writing, a final cost estimate and an agreed-upon schedule of payment.

Additional assistance to be provided by the library should function as a catchall for most items not covered above. Special research needs may not be clear until the approach to the particular problem is discussed. Computer time, or perhaps the availability of such implements as calculators or drafting tables, may be all that is necessary. In some instances payment of travel expenses and the availability of secretarial assistance are expected as well.

Once these topics have been discussed. thoroughly by the committee, the second goal is to establish a selection procedure to be followed in the next step of the organizational change process. The procedure might follow the steps laid out in the final section of the paper.

\section{SELECTION OF THE BEST- Qualified Consultant}

As with the two previous stages in the organizational change process, the selection procedure will vary according to the specific nature of the problem. Another factor affecting the selection procedure in general is the estimated number of qualified consultants available. It is possible that the few available experts on a given problem are known. In this case it may be advantageous to review published reports or visit former employers prior to contacting the consultant.

In general, however, it is wise to follow a standard procedure which gives less preference to the notability of an individual. After all, one factor in the quality of the final decision is the number of alternatives. Therefore, it is best to optimize this factor from the very beginning.

The first step in the procedure is the identification of suitable candidates for the job. Brief discussions of some of the relative advantages and disadvantages of individual consultants and firms of various sizes are presented elsewhere and will not be covered here. ${ }^{9}$

Typical sources utilized in obtaining names are state library agencies, the $\mathrm{Li}$ brary Administration Division of the American Library Association, colleagues who have dealt with similar problems recently, and directories. ${ }^{10}$ If the nature of the problem is such that specialists in that field are likely to be members of a particular professional association, it would be wise to contact that association. ${ }^{11}$

The second step, soliciting proposals, follows the period of preparation discussed in the previous section of the paper. The brief statement of the problem then is sent to likely candidates. Specifically, the desire for a brief proposal should be indicated as well as the probable procedure to be followed and 
the candidate's qualifications to perform such services. 'The committee should request supporting material in the form of reports, lists of similar undertakings, and a list of references from recent contractors.

The evaluation of the proposals is very important. It is of paramount concern that all statements and supporting documents be weighed in light of the requirements of the particular project on which the library is embarking. For example, does the consultant exhibit a basic understanding of the nature and scope of the particular task at hand? If so, are the approach and its probable consequences both practical and timely and consistent with the overall philosophy of library service at the institution? Having met these minimal qualifications, what merit does the proposal have when judged in light of the benefits and drawbacks of similar proposals?

Once a field of candidates has been narrowed down to the two or three most promising, it is necessary, and is considered common practice, to seek information as to the past performance of the individuals being considered. (If the services of a firm are under consideration, by all means determine exactly which individuals would be assigned, and their past records.) Such checks will provide more relevant information when the projects undertaken are similar in nature and scope to that intended for the project under consideration.

The following guidelines provide an approach to securing reference inquiry responses that are directly relevant to the selection discussion. After providing the reference with a brief statement of the work to be done, the following information should be requested:

1. How did the consultant's task in that organization differ from the work to be done?

2. How did the consultant meet commitments in terms of the items in Table 1 (Topics of Mutual Obli- gation and Agreement to Be Considered)?

3. What is the reference's overall evaluation of the consultant's work?

4. Would the reference retain the services of the same consultant again?

This should be done in person, if possible. Phone calls would prove more productive than letters, if personal contact is not possible. Personal contact allows for more open interaction as well as visual inspection of the work that was done (if appropriate).

Hopefully, by the time the interview stage is reached, one or two candidates stand out as the most appropriate choices. In that the host library normally pays the expenses of the interview trip, it is to the advantage of the library to limit the number invited.

The interview provides an opportunity for the consultant to determine local circumstances and to offer the host library staff an opportunity to discuss the proposed project, the prospective consultant's qualifications, and the specifics of the proposed solution.

The discussion of qualifications should include such topics as the consultant's familiarity with the practice of consulting; evidence of specific skills and knowledge of relevant theory; awareness of recent trends; professional activities, recent experiences; and especially participation in workshops or some form of continuing education.

The interview also allows the planning committee an opportunity to assess the prospective consultant's integrity, objectivity, analytic ability, level of energy, human relations and persuasive skills, maturity, and oral and written communications skills, both in the field of library science and in areas of his or her special competence. It is at this point that the committee must be wary of any guarantee of results, cost savings, or other such inducements. 
One individual should have a keen interest in the interview in particular. It is the liaison who must assess the potential quality of the working relationship with the consultant throughout the length of the entire change process.

Finally, the list of topics of mutual obligation and agreement must be discussed. This will enable clarifications to be made so that a contract may be agreed upon quickly in the event of an affirmative decision.

The final evaluation should be confidential. A frank discussion, perhaps with one committee member assigned the position of the devil's advocate, should bring out any matter needing further clarification.

\section{Conclusion}

The literature is not lacking for complaints about the work of consultants. ${ }^{12}$ In return, there is no lack of complaints on the part of consultants about those attempting to make use of their services. ${ }^{13}$ On the other hand, there is no shortage of complaints about projects undertaken, poor solutions attempted, and disastrous results achieved, all in libraries without the presence of any outside assistance at all.

All of this points to the importance of a rational decision-making process, from the point of awareness of a need for change. Once a tentative determination of the problem has been achieved it is necessary to ask questions about the nature of the information and analyses likely to be required to reach a satisfactory solution. Does the organization possess all of the expertise required to reach high-quality decisions? The answer to that question lies in the particular nature of the problem and the expertise of the staff. Once answered, the importance of sufficient time and objectivity also must be weighed.

A framework for determining the need for outside assistance was presented in the form of a decision model.
Once a need has been identified, preparation for and selection of the consultant also should follow a systematic procedure. By clearly specifying the committee's expectations, as well as the obligations of each participant, crucial steps for arriving at a satisfactory partnership have been accomplished.

By this point, the necessity for a consultant and the preferred relationship have been clarified. The final step in assuring the most promising progress toard the library's goal is to establish and carry out a systematic selection procedure such as that presented above.

To quote a common expression, "If you don't know where you are going, any road will take you there." This applies equally to libraries relying on their own staff as to those relying on poorly selected outsiders.

\section{REFERENCES}

1. Association of Consulting Management Engineers, Inc., Professional Practices in Management Consulting. (Rev. ed.; New York: The Association, 1966 ), p.17.

2. Library Buildings Institute, Chicago, 1963, Problems in Planning Library Facilities: Consultants, Architects, Plans and Critiques: Proceedings. Edited by William A. Katz and Roderick G. Swartz (Chicago: American Library Assn., 1964), p.12.

3. For example, the following are representative of the 1960s: Dorothy D. Corrigan and Hoyt R. Galvin, "Library Building Consulting, Problems and Ethics," ALA Bulletin 62:505-10 (May 1968); Ernest R. DeProspo, ed., The Library Building Consultant, Role and Responsibility; Report of a Seminar (New Brunswick, N.J.: Rutgers Univ. Pr., 1969); Ralph E. Ellsworth, "Consultants for College and University Library Building Planning," College \& Research Libraries 21:263-68 (July 1960); Library Buildings Institute, Problems in Planning Library Facilities; Nancy R. McAdams, "Super-Librarian and Sub-Architect: The Anomaly of the Role of the Building Consultant," Library Journal 91:5827-31 (Dec. 1, 1966); R. H. Rohlf, "The Consultant's Role," in Library Buildings: Innovation for Changing Needs; Proceedings of the Library Buildings Institute, San Francisco, June 22-24, 1967 (Chicago: American Library Assn., 1972), p.168-71. 
4. See, for example: John N. Berry, ed., $D i$ rectory of Library Consultants (New York: Bowker, 1969) and especially Ralph Blasingame's "Introduction"; A. W. Bowron, "Electric, Computer-Aided, User-Surveyed, Recycling Depot," British Columbia Library Quarterly 35:38 (Spring 1972); Keyes D. Metcalf, Planning Academic and Research Library Buildings (New York: McGraw-Hill, 1965) p.243; Rohlf, "The Consultant's Role," p.168; J. W. Allen, "Consult the Consultant," Industrial Research 17:46-47 (Jan. 1975); D. C. Caruth, H. J. Blender, and H. C. Sherwood, "Thinking of Using a Management Consultant?" Burroughs Clearing House 57:24-25 (June 1973); Neil G. Davey, The External Consultant's Role in Organizational Change (East Lansing: Michigan State Univ. Graduate School of Business Administration, 1971) p.27; Jerome H. Fuchs, Making the Most of Management Consulting Services (New York: AMACOM, 1975), chapter 2; A. M. Lederer, "Selecting a Management Consultant: Who, Why, and How," Administrative Management 34:61-62 (Aug. 1973); Philip W. Shay, How to Get the Best Results from Management Consultants (New York: Assn. of Consulting Management Engineers, Inc., 1974) p.3-4; N. Song, "Use and Abuse of Management Consultants," Management Review 63:35-36 (June 1974); C. D. Truckenbrodt, "Maximizing Return from a Management Consultant," Bankers Monthly 92:22-23 (Sept. 1975); "When Should You Call in a Consultant?," Administrative Management 23:68-72 (Feb. 1962).

5. Stanley C. Hollander, Management and Clients ( $2 \mathrm{~d}$ ed.; East Lansing: Michigan State Univ. Graduate School of Business Administration), 1972, p.141.

6. The basic decision tree model shown in Figure 1 is adapted from Victor $\mathrm{H}$. Vroom, "A New Look at Managerial Decision Making," Organizational Dynamics 1:66 (Spring 1973), who developed a similar model for determining the appropriateness of authoritative, consultative, or group decisions in organizational decision-making situations. For a portrayal of the types of expertise required in a specific situation and the typical locus of responsibility for each area of a library building project, see Stephen Langmead and Margaret Beckman, New Library Design: Guide Lines to Planning Academic Library Buildings (Toronto: Wiley, 1970), p.11825.
7. Vroom, "A New Look at Managerial Decision Making."

8. For some of the more thorough, see the following: Association of Consulting Management Engineers, Inc., Professional Practices in Management Consulting, p.37-41; J. Costello, "Cost of Hiring a Consultant," Nation's Business 63:6 (Sept. 1975); G. Duffy, "Consulting Engineer Firm Details Business Practices," Air Conditioning, Heating and Refrigeration News 133:3 (Sept. 30, 1974); Fuchs, Making the Most of Management Consulting Services, p.5163; Hollander, Management and Clients, introduction and table of contents; and Shay, How to Get the Best Results from Management Consultants, p.32-35.

9. Fuchs, Making the Most of Management Consulting Services, chapter 3; Hollander, Management and Clients, introduction; and Shay, How to Get the Best Results from Management Consultants, p.9-10.

10. Berry, Directory of Library Consultants; "Guide to Microfilm Consultants and Consulting Organizations," in Microfilm Source Book, 1974-5 (New Rochelle, N.Y.: Microfilm Publications, 1974), p.131-39; and a list of other directories can be found in Hollander, Management and Clients.

11. See, for example, American Psychological Association, Professional Affairs Committee, Division 14, "Proposed Guidelines for Choosing Consultants for Psychological Selection Validation Research and Implementation," reprinted in W. Clay Hamner and Frank L. Schmidt, Contemporary Problems in Personnel: Readings for the Seventies (Chicago: St. Clair Press, 1974), p.124-26.

12. For example: Berry, Directory of Library Consults, introduction; Murray L. Bob, "And a Consultant Shall Lead Them," $\mathrm{Li}$ brary Journal 94:44-45 (Jan. 1, 1969); Davey, The External Consultant's Role in Organizational Change, a study of factors influencing effectiveness; "The Debate over Licensing Consultants," Business Week (Aug. 3, 1974), p.18, see also editorial on p.64: "Liberty Not License"; Shay, How to Get the Best Results from Management Consultants, p.10-12; and E. N. SmithMontgomery, "How to Get the Worst from a Management Consultant," Business Management 40:16-18 (April 1971).

13. McAdams, "Super-Librarian and SubArchitect"; Richard Messing, "What Consultants Expect of Their Clients," Management Review 59:40-45 (May 1970); Smith-Montgomery, "How to Get the Worst from a Management Consultant." 